\title{
Acute kidney injury in a patient with COVID-19: Answers
}

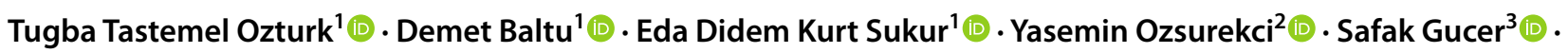

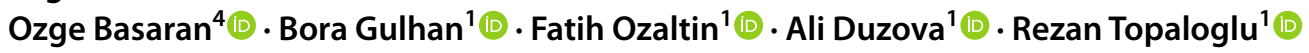

Received: 11 July 2021 / Accepted: 13 July 2021 / Published online: 7 September 2021

(c) IPNA 2021

Keywords Child · SARS-CoV-2 · COVID-19 · Acute kidney injury · Systemic lupus erythematosus

\section{Answers}

1. What are the possible causes of acute kidney injury in this patient?

One probable diagnosis in this patient was acute kidney injury associated with COVID-19. Although the main underlying mechanism is acute tubular damage secondary to hemodynamic changes, in COVID-19, collapsing glomerulopathy and thrombotic microangiopathy have also been demonstrated [1-3]. Renal tropism is a potential cause of kidney injury frequently reported in COVID-19 patients. An autopsy series showed by reverse transcriptase-PCR (RT-PCR) in kidney tissues that SARS-CoV-2 could directly infect the renal parenchyma [4].

Another probable diagnosis in this adolescent girl presenting with rapidly progressive glomerulonephritis (RPGN) and psychiatric symptoms for some time was systemic lupus erythematosus (SLE).

Anti-neutrophil cytoplasmic antibody (ANCA)-associated vasculitis should have been ruled out considering the

This refers to the article that can be found at http://dx.doi.org/10. 1007/s00467-021-05233-2.

Tugba Tastemel Ozturk

t_tastemel@hotmail.com

1 Division of Pediatric Nephrology, Faculty of Medicine, Hacettepe University, Sihhiye, 06100 Ankara, Turkey

2 Department of Pediatric Infectious Diseases, Faculty of Medicine, Hacettepe University, Ankara, Turkey

3 Department of Pathology, Faculty of Medicine, Hacettepe University, Ankara, Turkey

4 Division of Pediatric Rheumatology, Faculty of Medicine, Hacettepe University, Ankara, Turkey
RPGN and the nodular lesions on thorax CT. The literature includes data on two adult patients diagnosed with ANCAassociated vasculitis and COVID-19 simultaneously [5].

\section{What additional tests would you perform?}

Complement 3, 4, anti-nuclear antibody (ANA), anti-double-stranded DNA antibody (anti-ds DNA), antiphospholipid antibodies assessments for SLE, SARS-CoV-2 analysis by PCR in kidney tissue, and anti-neutrophil cytoplasmic antibodies for ANCA-associated vasculitis.

3. What is the most likely diagnosis in this patient in view of the histopathological findings?

Systemic lupus erythematosus is the most likely diagnosis in this patient in view of the histopathological findings. Pathological examination showed diffuse proliferative lupus nephritis (class IV).

\section{How should this patient be managed?}

Anti-proliferative immunosuppressive treatment should be started immediately while balancing its potential effects on the COVID-19 course.

Low serum complement (C3: $43 \mathrm{mg} / \mathrm{dL}, \mathrm{C} 4: 4.9 \mathrm{mg}$ / dL), 1/640 ANA, and positive anti-ds DNA (271 IU/mL) were compatible with SLE, and histopathological findings of the patient were consistent with class 4 SLE nephritis. Serum antiphospholipid antibodies and ANCA profile were negative. SARS-CoV-2 in the kidney tissue was evaluated by PCR and found negative. On the 15 th day of admission, taking the rapid improvement of COVID-19 pneumonia into account, intravenous cyclophosphamide was given to the patient. Two weeks after the first cycle of immunosuppressive treatment, bolus methylprednisolone 
and cyclophosphamide treatments were repeated. By the end of 1 month, the patient's ascites partially regressed, and her serum creatinine levels decreased to $0.8 \mathrm{mg} / \mathrm{dL}$. Considering severe renal histopathological findings and $30 \mathrm{~g} /$ day proteinuria, a third bolus of methylprednisolone and cyclophosphamide treatments was given 2 weeks after the second doses.

To rule out central nervous system involvement of SLE, a contrast-enhanced imaging was required; however, a non-contrast cranial magnetic resonance imaging (MRI) was normal. Contrast-enhanced imaging has been scheduled.

\section{Discussion}

In COVID-19, which emerged in 2019 and turned into a global pandemic, the primary target is the lung but the disease often involves other systems. The kidneys are among the most affected organs. In a recently published study, COVID-19-related acute kidney injury incidence in children was 8\% (8/97) [6]. The main mechanism in COVID-19-related acute kidney injury has been shown to be renal tubular damage secondary to hemodynamic changes. In a study evaluating kidney biopsies of ten adult patients with COVID-19 and acute kidney injury, varying degrees of acute tubular necrosis were reported in all patients [1]. Similarly, another study showed diffuse proximal tubular damage accompanied by brush border irregularity among 26 postmortem kidney biopsies of adult COVID-19 patients [2]. Various other glomerular pathologies have also been described. Collapsing glomerulopathy associated with COVID-19 most commonly affects individuals with high-risk APOL1 polymorphisms [3]. In a biopsy series, thrombotic microangiopathy was reported in two, and crescentic glomerulonephritis in one, out of ten COVID-19-related acute kidney injury patients [1]. Direct renal invasion of the virus was also described; coronavirus particle clusters in the tubular epithelium and podocytes by electron microscopy and viral load by RT-PCR were demonstrated [2, 4]. In our patient, SARSCoV-2 was negative by PCR in the kidney tissue, and there were no signs of collapsing glomerulopathy or thrombotic microangiopathy.

After the adult de novo ANCA-associated glomerulonephritis and COVID-19 cases, two pediatric patients with COVID-19-related necrotizing glomerulonephritis have been reported $[5,7]$. In our differential diagnosis, we also considered ANCA-associated vasculitis based on the nodular lesions on thorax $\mathrm{CT}$ and the rapidly progressing GN. However, the ANCA profile of our patient turned out to be negative, kidney biopsy findings were not compatible with ANCA-associated vasculitis, and lung findings were of COVID-19 pneumonia.
Systemic lupus erythematosus is a multisystemic, chronic autoimmune disease that may affect every organ and tissue. In a recent childhood-onset SLE study from our center, we found that the most common manifestations at the time of SLE diagnosis were cutaneous (69.6\%) and hematological involvement (62.7\%), and renal disorders were observed with a frequency of $42.2 \%$. In this study, at the time of LN diagnosis, $33.3 \%$ of patients had nephrotic range proteinuria, and only $7.5 \%$ had a GFR $<30 \mathrm{~mL} / \mathrm{min} / 1.73 \mathrm{~m}^{2}$ [8]. Cutaneous or hematological findings related to SLE were not present in our patient at the time of diagnosis. She had clinical RPGN and the biopsy showed diffuse proliferative lupus nephritis. We believe the absence of chronicity findings in the kidney biopsy indicated that renal activation of SLE coincided with COVID-19. The cranial MRI of our patient, who was having psychiatric problems for 2 years, was found normal; contrast-enhanced cranial MRI is scheduled to be performed.

SARS-CoV-2 infection can lead to autoimmune and rheumatological manifestations by molecular mimicry (crossreacting epitope between the virus and the host), bystander killing (virus-specific CD8 $+\mathrm{T}$ cells migrating to the target tissues and exerting cytotoxicity), epitope spreading, viral persistence (polyclonal activation due to the constant presence of viral antigens driving immune-mediated injury), and formation of neutrophil extracellular traps [9]. SARSCoV-2 infection enhances the release of multiple cytokines, such as IL-1b, TNF- $\alpha$, IL-6, IL-7, IL-8, IL-9, and IL-10, and the intensive release of multiple cytokines may trigger a cytokine storm that produces immunopathogenic damage to tissues [10-12]. We believe that the inflammatory state secondary to COVID-19 might have contributed to the kidney tissue damage, and intensified the autoimmune damage of SLE. Accordingly, adult SLE patients (18-85 years) presenting simultaneously with or 2 months after SARS-CoV-2 infection have been reported; some had renal involvement among whom one had a kidney biopsy showing class I lupus nephritis [13-17].

To our knowledge, this patient is the first pediatric case published with diffuse proliferative lupus nephritis possibly triggered by COVID-19. Based on the absence of chronicity findings in the kidney biopsy, we believe that renal activation occurred simultaneously with COVID-19. Although kidney damage is common during COVID-19, autoimmune diseases involving the kidney should also be kept in mind in these patients.

Data availability Not applicable.

Code availability Not applicable. 


\section{Declarations}

Ethics approval Not applicable.

Consent to participate Informed consent was obtained from the parents.

Consent for publication Not applicable.

Conflict of interest The authors declare no competing interests.

\section{References}

1. Sharma P, Uppal NN, Wanchoo R, Shah HH, Yang Y, Parikh R, Khanin Y, Madireddy V, Larsen CP, Jhaveri KD, Northwell Nephrology COVID-19 Research Consortium (2020) Bijol V 2020 COVID-19-associated kidney injury: a case series of kidney biopsy findings. J Am Soc Nephrol 31:1948-1958. https:// doi.org/10.1681/ASN.2020050699

2. Su H, Yang M, Wan C, Yi LX, Tang F, Zhu HY, Yi F, Yang HC, Fogo AB, Nie X, Zhang C (2020) Renal histopathological analysis of 26 postmortem findings of patients with COVID-19 in China. Kidney Int 98:219-227. https://doi.org/10.1016/j.kint. 2020.04.003

3. Ng JH, Bijol V, Sparks MA, Sise ME, Izzedine H, Jhaveri KD (2020) Pathophysiology and pathology of acute kidney injury in patients with COVID-19. Adv Chronic Kidney Dis 27:365-376. https://doi.org/10.1053/j.ackd.2020.09.003

4. Puelles VG, Lütgehetmann M, Lindenmeyer MT, Sperhake JP, Wong MN, Allweiss L, Chilla S, Heinemann A, Wanner N, Liu S, Braun F, Lu S, Pfefferle S, Schröder AS, Edler C, Gross O, Glatzel M, Wichmann D, Wiech T, Kluge S, Pueschel K, Aepfelbacher M, Huber TB (2020) Multiorgan and renal tropism of SARS-CoV-2. N Engl J Med 383:590-592. https://doi.org/10. 1056/NEJMc2011400

5. Uppal NN, Kello N, Shah HH, Khanin Y, De Oleo IR, Epstein E, Sharma P, Larsen CP, Bijol V, Jhaveri KD (2020) De novo ANCA-associated vasculitis with glomerulonephritis in COVID19. Kidney Int Rep 5:2079-2083. https://doi.org/10.1016/j.ekir. 2020.08.012

6. Basalely A, Gurusinghe S, Schneider J, Shah SS, Siegel LB, Pollack G, Singer P, Castellanos-Reyes LJ, Fishbane S, Jhaveri KD, Mitchell E, Merchant K, Capone C, Gefen AM, Steinberg J, Sethna CB (2021) Acute kidney injury in pediatric patients hospitalized with acute COVID-19 and multisystem inflammatory syndrome in children associated with COVID-19. Kidney Int 100:138-145. https://doi.org/10.1016/j.kint.2021.02.026

7. Basiratnia M, Derakhshan D, Yeganeh BS, Derakhshan A (2021) Acute necrotizing glomerulonephritis associated with COVID-19 infection: report of two pediatric cases. Pediatr Nephrol 36:10191023. https://doi.org/10.1007/s00467-021-04944-w
8. Demir S, Gülhan B, Özen S, Çeleğen K, Batu ED, Taş N, Orhan D, Bilginer Y, Düzova A, Ozaltin F, Topaloğlu R (2021) Long term renal survival of pediatric patients with lupus nephritis. Nephrol Dial Transplant. https://doi.org/10.1093/ndt/gfab152

9. Shah S, Danda D, Kavadichanda C, Das S, Adarsh MB, Negi VS (2020) Autoimmune and rheumatic musculoskeletal diseases as a consequence of SARS-CoV-2 infection and its treatment. Rheumatol Int 40:1539-1554. https://doi.org/10.1007/ s00296-020-04639-9

10. Huang C, Wang Y, Li X, Ren L, Zhao J, Hu Y, Zhang L, Fan G, Xu J, Gu X, Cheng Z, Yu T, Xia J, Wei Y, Wu W, Xie X, Yin W, Li H, Liu M, Xiao Y, Gao H, Guo L, Xie J, Wang G, Jiang R, Gao Z, Jin Q, Wang J, Cao B (2020) Clinical features of patients infected with 2019 novel coronavirus in Wuhan, China. Lancet 395:497-506. https://doi.org/10.1016/S0140-6736(20)30183-5

11. Qin C, Zhou L, Hu Z, Zhang S, Yang S, Tao Y, Xie C, Ma K, Shang K, Wang W, Tian DS (2020) Dysregulation of immune response in patients with Coronavirus 2019 (COVID-19) in Wuhan, China. Clin Infect Dis 71:762-768. https://doi.org/10. 1093/cid/ciaa248

12. Sun X, Wang T, Cai D, Hu Z, Chen J, Liao H, Zhi L, Wei H, Zhang Z, Qiu Y, Wang J, Wang A (2020) Cytokine storm intervention in the early stages of COVID-19 pneumonia. Cytokine Growth Factor Rev 53:38-42. https://doi.org/10.1016/j.cytogfr. 2020.04.002

13. Bonometti R, Sacchi MC, Stobbione P, Lauritano EC, Tamiazzo S, Marchegiani A, Novara E, Molinaro E, Benedetti I, Massone L, Bellora A, Boverio R (2020) The first case of systemic lupus erythematosus (SLE) triggered by COVID-19 infection. Eur Rev Med Pharmacol Sci 24:9695-9697. https://doi.org/10.26355/eurrev_202009_23060

14. Zamani B, Moeini Taba SM, Shayestehpour M (2021) Systemic lupus erythematosus manifestation following COVID-19: a case report. J Med Case Rep 15:29. https://doi.org/10.1186/ s13256-020-02582-8

15. Mantovani Cardoso E, Hundal J, Feterman D, Magaldi J (2020) Concomitant new diagnosis of systemic lupus erythematosus and COVID-19 with possible antiphospholipid syndrome. Just a coincidence? A case report and review of intertwining pathophysiology. Clin Rheumatol 39:2811-2815. https://doi.org/10.1007/ s10067-020-05310-1

16. Gracia-Ramos AE, Saavedra-Salinas MÁ (2021) Can the SARS$\mathrm{CoV}-2$ infection trigger systemic lupus erythematosus? A casebased review. Rheumatol Int 41:799-809. https://doi.org/10.1007/ s00296-021-04794-7

17. Hali F, Jabri H, Chiheb S, Hafiani Y, Nsiri A (2021) A concomitant diagnosis of COVID-19 infection and systemic lupus erythematosus complicated by a macrophage activation syndrome: a new case report. Int J Dermatol. https://doi.org/10.1111/ijd.15592

Publisher's note Springer Nature remains neutral with regard to jurisdictional claims in published maps and institutional affiliations. 